\title{
Tumor-derived extracellular vesicles: reliable tools for Cancer diagnosis and clinical applications
}

\author{
Reza Rahbarghazi ${ }^{1,2}$, Nasrollah Jabbari3 ${ }^{3,4}$, Neda Abbaspour Sani ${ }^{3}$, Rahim Asghari, ${ }^{3,5}$, Leila Salimi ${ }^{1}$, \\ Sadegh Asghari Kalashani ${ }^{6}$, Maryam Feghhi ${ }^{4}$, Tahereh Etemadi ${ }^{7}$, Elinaz Akbariazar ${ }^{8}$, Mahmoud Mahmoudi ${ }^{9}$ and \\ Jafar Rezaie ${ }^{3 *}$ (D)
}

\begin{abstract}
Background: Studies have recently revealed that almost every type of cells including tumor cells abundantly release small vesicles known as extracellular vesicles (EVs) into the extracellular milieu. EVs carry a repertoire of biological molecules including nucleic acids, proteins, lipids, and carbohydrates and transport their cargo between cells in the vicinity as well as distantly located cells and hence act as messengers of intercellular communication. In this review, we aimed to discuss the tumor-derived exosome biology and the pivotal roles of exosomes in cancer diagnosis and treatment.

Methods: In the present review study, the authors studied several articles over the past two decades published on the kinetics of EVs in tumor environment as well as on the application of these vesicles in cancer diagnosis and therapy.

Results: A growing body of evidence indicates that nucleic acids such as microRNAs (miRNAs) transferring by EVs participate to create a conducive tumor environment. As EV-associated miRNAs are tissue-specific and present in most biological fluids, they hold great potential for clinical application in cancer early diagnosis, prognosis, and treatment response. Furthermore, exosomes can serve as drug delivery vehicles transferring miRNAs as well as therapeutic agents to target cells. These nano-vesicles exhibit ideal properties in comparison with the synthetic carriers that attracted scientist's attention in the field of nanotechnology medicine. Scientists have employed different strategies to build exosomes-based drug delivery system. In general, two methods (direct engineering and indirect engineering) are being utilized to produce artificial exosomes. Para-clinical data have confirmed the beneficial effects of engineering exosomes in cancer therapy.

Conclusion: Exosomal miRNAs hold great promise for clinical application in early diagnosis and treatment of cancers. In addition, in spite of enthusiastic results obtained by engineered exosomes, however, there is an increasing concern over the use of optimal methods for engineering exosomes and the safety of engineered exosomes in clinical trials is still unclear.
\end{abstract}

Keywords: Extracellular vesicles, Cancer, miRNA, Biomarker, Drug delivery

\footnotetext{
* Correspondence: J.rezaie88@gmail.com; Rezaie.j@umsu.ac.ir

${ }^{3}$ Solid Tumor Research Center, Cellular and Molecular Medicine Institute,

Urmia University of Medical Sciences, Shafa St, Ershad Blvd., P.O. BoX: 1138,

Urmia 57147, Iran

Full list of author information is available at the end of the article
}

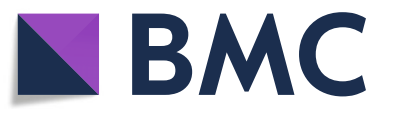

(c) The Author(s). 2019 Open Access This article is distributed under the terms of the Creative Commons Attribution 4.0 International License (http://creativecommons.org/licenses/by/4.0/), which permits unrestricted use, distribution, and reproduction in any medium, provided you give appropriate credit to the original author(s) and the source, provide a link to the Creative Commons license, and indicate if changes were made. The Creative Commons Public Domain Dedication waiver (http://creativecommons.org/publicdomain/zero/1.0/) applies to the data made available in this article, unless otherwise stated. 


\section{Background}

Cancer, the second reason for mortality worldwide, has grown to be a global health issue during past decades [1] In a tumor environment, the tumor cells exhibit unique characteristics such as their co-option with surrounding cells and soluble factors, uncontrolled growth, immune evasion and resistance to therapies [2]. Early identification of tumor is a pivotal factor in cancer therapy that improves survival and quality of a patient's life [3]. There are possible challenges in the invasive biopsy technique, which biopsies samples may don't represent exact information about heterogeneous tumor tissue. Additionally, it may cause stimulation in tumor growth rate and metastasis [4]. Alternatively, liquid biopsy is a simple and non-invasive way to inform clinicians about the tumor progression through a bio-fluid sampling such as blood sampling [5]. Recent studies suggested that tumor condition could be monitored by cell-derived nanoparticles named EVs which carry biomolecules including mRNA, miRNAs, DNA, proteins, and lipids [6]; as well as long-non coding RNAs [7] contribute to the intercellular communication. It has been shown that EVs contain the information of tissue of their origin [8]. Researchers have demonstrated that EVs including exosomes provide a critical and sensitive source of biomarkers in almost pathological condition [9-11]. Exosomes, a subtype of extracellular vesicles (EVs), are cell-derived biopolymers in the range of $30-120 \mathrm{~nm}$ in diameter, which have unique structural, biochemical and mechanical properties [12]. These vesicles encompassing bio-molecules including mRNA, miRNAs, DNA, proteins, and lipids; contribute to the intercellular communication. In tumor cells, exosome biogenesis, and loading mechanisms is a complex and regulated process, and many different molecules passively and/ or actively involved in to form exosomes [13]. As exosomes distribute through bio-fluids, they are more accessible through simple liquid sampling. Thus, by analyzing the exosomal miRNAs signature, scientists are capable of understanding secreting cell status and eventually tumor condition [14]. Furthermore, due to shuttling various biomolecules, there is an idea that exosomes can be used for cancer therapy by delivering therapeutic agents [15]. Exosomes pose such favorable characteristics that make them superior to traditional nano-delivery modules. For example, exosomes are cell-derived particles, therefore, exhibit more safety and stable property than other delivery compounds such as liposomes [16]. Besides, they specifically deliver cargoes to the distant target sites, even they pass through the blood-brain barrier [16]. In this regard, laboratories have examined the possible therapeutic potential of exosomes by sorting miRNAs and therapeutic compounds into exosomes in vitro and in animal models [17, 18]. Various strategies have been employed for loading therapeutic agents into exosomes and authors tracked efficacy and specificity of exosome-based drug delivery system in the in vitro and in vivo models $[19,20]$. In this review, we discuss the recent progress in the exosome kinetic, especially crucial roles of exosomal miRNAs in the tumor microenvironment and their application in cancer diagnosis. In addition, we review the last knowledge about strategies used to engineer and form optional exosomes and also explain examples of the therapeutic agents sorted into exosomes.

\section{Biology of extracellular vesicles}

Recent progress in molecular medicine described the key roles of EVs in cell biology. Especially, EVs are introduced as intercellular messenger in physiological and pathological conditions [13]. They encompass a large number of bio-martial such as RNAs, DNA strands, proteins, and also lipids [21]. According to evidence, three subpopulations of EVs were detected based upon the biogenesis mechanism and the size of vesicles diameter [22]. Exosomes, the 30-120 nm member of EVs, releasing from almost different types of mammalian cells through the endocytotic pathway [23]. Interestingly, recent scrutiny on exosomes purification has identified two distinct subpopulations of exosomes according to their size and compositions [24]. Exosomes distribute both in cell culture medium and body bio-fluids including blood, CSF, urine, and breast milk [25]. Exosome biogenesis is an intracellular complex mechanism that various types of molecules including endosomal sorting complex required for transport (ESCRT) assembly, lipid molecules, accessory proteins, Rab-GTPase family, and soluble NSF attachment protein receptors (SNAREs) proteins contribute to regulating exosome formation, loading, and releasing [20, 26] (Fig. 1). Beside transferring various molecules, exosomes have been shown to express the conventional markers including CD63, CD82, CD9, CD81, ALIX, and also TSG101 [23]. Multivesicular bodies (MVBs) are late endosome compartments located in the cytoplasm, assigned to generate exosomes. Previous experiments have confirmed that mature MVBs have three intracellular fates (Fig. 1); secretory, lysosomal, and back fusions fates [27]. In the secretory pathway, MVBs could combine with the plasma membrane (PM) and unload vesicles named exosomes into the extracellular matrix (ECM). Once exosomes distributed to the ECM, they try to target cells in proximity or in faraway. Scientists supposed three possible ways that exosomes contribute to affect recipient cell function (Fig. 1); (i) internalization; (ii) receptor-ligand interaction; (iii) direct fusion [27, 28]. Internalization pathway is a traditional way to import exosomes, where exosomal cargoes contribute to affect signaling pathways in recipient cells. Another way is ligand-receptor interaction, in this way exosomal surface molecules interact with molecules located on the PM of target cells [29]. In direct-type fusion, these vesicles may well directly fuse with the PM of recipient cells through engaging common 


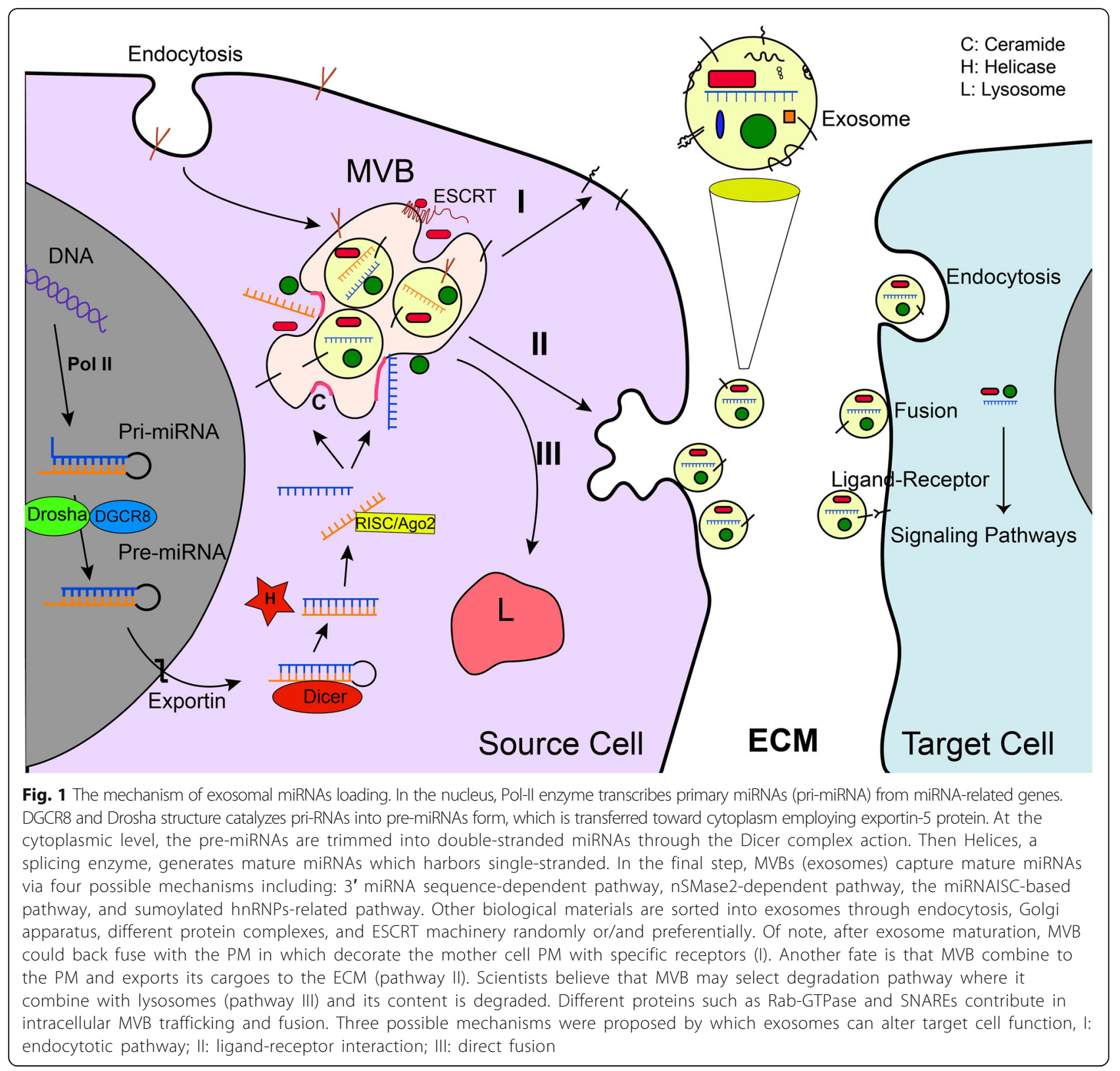

fusion-related molecules such as SNAREs. Emerging evidence for further uptake ways has been reported, for example, protease located in the ECM may be responsible of activation of exosomal proteins/enzymes that in turn, they contribute to interact with target cells receptors as a ligand, then induce receptor-related downstream signaling [30]. Microvesicles (MVs), $100-1000 \mathrm{~nm}$ vesicles, a subtype of EVs, are released from various cells including plates and endothelial cells (ECs). There is a consensus that MVs are made by the mechanism that the PM abscises encompassing cytoplasm materials. These vesicles are irregular in shape, heterogeneous in size and different in contents based on maternal cell physiological status [31, 32]. The largest subclass of EVs $(1-6 \mu \mathrm{m}$ in diameter) is apoptotic bodies
(ABs), deriving from cells undergoing apoptosis [33]. There appears to be a consensus of opinion that $\mathrm{ABs}$ formation occurred when caspase- 3 activates a kinase, in turn, that kinase phosphorylates myosin light chain and initiates splitting cells up into segmentations [34]. ABs harbor cytoplas mic components, therefore, they may mediate communication signaling among target cells and progress adverse effects in several diseases [35]. Recent trends in the kinetic of EVs contributed to the launch of the International Society for Extracellular Vesicles (ISEV, www.isev.org), which is a worldwide society of leading EVs, exosomes, and MVs researchers. ISEV internationally authorized to advance EVs research and instruction including refreshes the terminology, categorization, isolation, characterization, 
and functional analysis. In addition, with more than 1,000 members, ISEV organization all around interfaces top scientists at its annual meeting, workshops and different occasions. To date, there are databases such as ExoCarta (www.exocarta.org), Vesiclepedia (www. microvesicles.org), and EVpedia (www.evpedia.info) assembling exosomal contents for the researchers. This fact globally shows the significance of EVs in biological systems and also in the field of disease management. Nowadays, scientists interested in the field of clinical application of EVs in various diseases such as cancers. In the case of cancers, the interesting aspects of EVs are the diagnosis, prognosis, and therapeutic potentials.

\section{Exosome cargoes}

Exosomes are spheroid particles composed of a bilayer lipid membrane structure that decorated themselves surface with various ligands and receptors harbored from parental cells. In addition, their lumen contains various biomolecules such as nucleic acids, carbohydrates, and proteins [36]. Recent progress in the field of exosome isolation and characterization led to considerable interest in the discovery of exosomes cargoes because exosomal molecular cargoes can increase our knowledge about underlining mechanisms involved in biogenesis and function of exosomes; especially, cargoes may serve as biomarkers and therapeutic agents for various disease diagnosis and treatment [37]. Nevertheless, there is evidence that suggests exosomes from different source exhibit even common molecules. For instance, as exosomes are manufactured from the endocytotic pathway, they inherit endosomal components such as Alix and Tsg101 molecules. Other molecules for example tetraspanins (CD63, CD81, and CD9), intracellular trafficking molecules (Rab-GTPase family and SNAREs), membrane molecules (integrins, adhesion molecule 1 (ICAM-1)), cytoskeletal components (tubulin, actin, and annexins) are traditionally present in almost exosomes [38, 39]. As well, previous studies have reported that common lipids for instance phosphatidylethanolamine, diacylglyceride, ceramides, phosphatidylserine, also-bisphospatidic acid, cholesterol, and sphingomyelin are present in exosomes [40]. In addition, for the first time, the existence of nucleic acids in cargoes of exosomes has been detected in exosomes from mast cells [41]. After that, growing evidence confirmed the existence of different kind of the mRNAs and miRNAs in various exosomes. It seems that a complex sorting mechanism is involved in the exosomal loading process rather than a random process [42]. Of note, cells preferentially engage complicated mechanisms to sort specific nucleic acids to the exosomal secretory pathway [43]. Interestingly, it has been demonstrated that in the pathological condition exosomes cargoes are different from in the normal one. Thus, parental cell status may be disclosed by analyzing the composition of isolated exosomes and discrimination between the types of components can be used as a pivotal biomarker of disease [44]. Stress condition is another factor that influences exosomes cargoes. For example, there is a growing body of evidence that ionizing radiation [45] and hypoxia [46] not only increase exosome secretion rate but also alter exosome cargoes. More recently, a database (http://bioinfo.life.hust.edu.cn) has established to present 462 small RNA sequencing samples of EVs from 17 sources which show miRNA expression profile in different EVs [47]. Another informative database, Exocarta (http://www.exocarta.org), the globally exosomal database, categorized 1,639 mRNAs, 4764 miRNAs, 563 proteins, and 194 lipids based on organisms [48]. Similarly, Vesiclepedia (http://www.microvesicles.org) is an exosome-related database that prepared a large number of data about exosomes cargoes from various studies. This web has collected 1254 EVs studies and categorized approximately 349988 proteins, 38146 various RNAs, 639 lipids [49]. Collectively, these facts show that exosomes act as bio-container transferring a large number of biomolecules and different cells release various exosomes with distinct contents.

\section{Exosomal miRNA loading}

It seems that the exosome loading process is complex and mediated by different biomolecules located on MVBs membrane [26] and there is a little information about underlying mechanisms [22]. However, it has been uncovered that the ESCRT complex contributes to packaging-specific molecules into exosomes. In this scenario, different biological components may be trapped constitutively or randomly during exosomes biogenesis [13]. As it is known, small RNAs such as miRNAs, small non-coding RNAs, be composed of 22 nucleotides, expressed in eukaryotes and even in a number of viruses [50]. Based on previous studies, miRNAs are generated in a precursor form called premiRNAs (Fig. 1). This miRNA interconnected with the performing compound including argonaute2 (Ago2), human embryonic lethal abnormal visual (ELAV proteins or human antigen $\mathrm{R}(\mathrm{HuR})$, Dicer, and various RNA-binding proteins (RBPs) which make mature miRNAs in the cytoplasm. Finally, mature miRNAs contribute to blockage RNA translation; therefore, regulate mRNAs fate (Fig. 1). In fact, studies of miRNAs function indicate that miRNAs inhibit mRNA molecules through three possible mechanisms; I: segmentation of the mRNA strands, II: destabilization of the mRNAs, and III: inhibition of the mRNA- ribosomes interaction [51, 52]. Study of exosome biogenesis process shows the importance of sphingomyelinase 2 (nSMase2) in the loading of exosomal miRNAs [53]. A possible explanation is that nSMase 2 catalyzes the formation of ceramide, which promotes exosome formation and miRNA trapping. 
In support, it has been reported that the interrupting of nSMAse2 activity blocks exosomes secretion [54]. Besides, exosomal packaging of miRNAs is regulated through a sequence-dependent mechanism and mediated by chaperone proteins [43]. A work conducted by Villarroya-Beltri et al. [55] declared that the hnRNPA2B1 protein, associated with emerging premRNAs, packaging pre-mRNAs into hnRNP particles, participate to target specific miRNAs into exosomes. Interestingly, $3^{\prime}$ end sequences of miRNAs is a landmark for effector proteins to determine whether miRNAs are reserved in the intracellular pool or engaged for export via exosomes. For example, it was approved that presence of 1,2 or 3 adenosine or uridine nucleotides in the $3^{\prime}$ end of miRNA may direct miRNA to exosomes. Interestingly, poly-U miRNAs are packaged into exosomes while poly-A miRNAs probably remain in the cytoplasm [56]. Moreover, in comparison to the cell, exosomes transfer low volume of ribosomal RNA (rRNA) such as $28 \mathrm{~s}$ and $18 \mathrm{~s}$ rRNA and RNAs content of exosomes differ to cellular content [41]. A large of evidence supports the fact that RBPs contribute to sorting special RNAs into exosomes. For example, RNAs in association with Ago2, a type of RBPs, and high-density lipoprotein components were discovered in an extracellular milieu in the form of EVs-linked or free of EVs. It is reasonable that RBPs may protect RNAs in extracellular space and inside exosomes $[57,58]$. A work conducted by Steatello and colleagues identified 30 RBPs in exosomes that contribute to forming RBP-RNA complexes. Notably, authors by doing functional experiments on 6 RBPs genes showed that MVP is a key member of RBRs that regulate sorting process of RNAs into exosomes and protect them inside exosomes in ECM [59]. Alike, tumor-derived exosomes potentially transfer miRNAs linked to the RISC-Loading Complex (RLC). In addition, complex molecules such as Dicer, TRBP, AGO2, and also pre-miRNA, were associated with exosomes of cancer cells. Besides delivering mature miRNAs, it seems that exosomes contribute to the development of precursor pre-miRNA into mature form by a cell-free mechanism in the cytoplasm of recipient cells [60]. A work on colorectal cancer cells showed that the exosomal loading mechanism is a KRAS-dependent and KRAS-mutant cells abundantly release miRNA-100 while normal KRAS cells sort a high volume of miRNA-100 to the exosomes lumens incorporation with nSMAse [61]. Recent evidence suggests that KRAS/ MEK/ERK signaling pathway may abolish the packaging of AGO2-linked miRNAs into exosomes [62]. These findings indicate that exosomal miRNA loading is a tightly regulated mechanism.
However, most of the exosome-based studies have only described exosomal miRNAs profiling of different cancer cells and there is a little knowledge about miRNAs loading mechanisms [63]. Furthermore, by which mechanisms RNA-protein complexes are selected by MVBs and how RNA molecules preserved in exosomes still remain elusive. Noticeably, several attempts have been made to assay effect of environmental condition on exosomes loading rate and composition. For instance, Jung and the co-workers showed that hypoxia altered breast cancer cells derived exosomes miRNAs content, so that miRNA-210 was abundantly burdened into those exosomes [64]. Ionizing radiation is another stress factor that influences exosome formation and loading through p53/ tumor suppressor activated pathway 6 (TSAP6) signaling pathway [45]. In this sense, the p53/ TSAP6 axis has been shown to mediate exosomal miRNAs loading process following DNA damage. In an analysis of exosomal miRNAs content from different tumor cells lines, Langevin et al. found that there was noteworthy dissimilarity in the miRNAs profile of exosomes among tumor cells and normal ones [65]. Thus, at least, the miRNA loading system in tumor cells selectively introduces specific miRNAs to exosomes generator compartments based on cell condition [34]. The central questions, in this case, are: Do different cells use the same mechanism to load miRNAs into exosomes? And; in different conditions, which miRNA loading mechanism is involved?

\section{Role of exosomal miRNAs in cancer biology}

Enriched in exosomes, miRNAs transmitted into target cell cytoplasm and participate to regulate mRNAs expression and cell function of target cell [41]. Evidently, exosomal miRNAs attracted scientific attentions have pivotal roles in spreading the adverse effects of tumors [66]. Cancer cells release more exosomes to promote many aspects of tumors malignity including proliferation, invasion, metastasis, angiogenesis, and immunosuppression [67]. In the case of proliferation, in human nasopharynx cancer, tumor-released exosomes actively transfer onco-miRNAs such as miRNA-106a-5p, miRNA891a, miRNA-24-3p, and miRNA-20a-5p that promote cell proliferation through inhibition of MARK1 protein signaling pathway [68]. Conversely, in lung carcinoma cell lines, 95C and 95D cell derived exosomes deliver miRNA$302 \mathrm{~b}$ to target cells and cause cell growth inhibition by the TGFßRII/ERK signaling pathway [69]. Kogure and colleague declared that exosomal miRNA-584 is capable of accelerating hepatocellular cancer cells proliferation [70]. Several researchers have emphasized that oncogenic exosomal miRNAs are capable of inducing metastasis and aggressive mass out of the tumor location. For example, it was previously documented that tumor-derived exosomes by miRNA-29a and miRNA-21 contribute to tumor cell proliferation and invasion. It seems that activation of NF- 
$\kappa \mathrm{B}$ by toll-like receptors (TRL) downstream signaling in immune cells led to producing cytokines from immune cells that amplify tumor cell division and metastatic rate [71]. It was represented that tumor-released miRNAs act as a ligand for TLR family, human TLR8, and murine TLR7 in immune cells that promote pro-metastatic inflammatory factors and eventually results in tumor cell movement and aggressiveness [72]. In addition, miRNA105 loaded exosomes from cancerous cells stimulating invasion to the brain and respiratory system; act as a ZO-1 inhibition agent in ECs and facilitate cell migration [73]. In this regard, miRNA- 21 bearing exosomes stimulate the invasion and relocation of esophageal tumor cells via activating PDCD4 / JNK axis in recipient cells [74]. Furthermore, in another study, exosomal miRNA-122 from breast tumor cells contributes to rearrange glucose metabolism, in turn, promotes metastasis niche formation [75]. In addition, rat BSp73ASML cancerous cells contain onco-miRNAs such as miRNA-494 and miRNA-542-3p that regulate the formation of cadherin- 17 and matrix metalloproteinase (MMPs) hence promote the formation of a pre-metastatic niche in recipient host tissues [76]. Recently, investigators have examined the effects of tumor-derived exosomal miRNAs on the angiogenesis. Angiogenesis, raising new capillary from preexistent vessels, is a critical key in tumor expansion stimulated by tumor hypoxic environment [77]. The potential relationship between exosomal miRNAs and angiogenesis has arisen from the observation that hypoxic A549 lung tumor cells secret miRNA-494 bearing exosomes that delivered to neighboring ECs and encouraged the angiogenic potential through inducing Akt/eNOS axis and block of PTEN protein [78]. Moreover, miRNA-21 released by exosomes from lung tumor cells by way of STAT3 signaling and VEGF generation promotes angiogenesis in non-tumor lung cells [74]. Chronic lymphocytic leukemia cells release exosomal miRNAs targeting mesenchymal stem cell (MSCs) and ECs that leading to force cells to produce pro-angiogenic molecules [79]. Additionally, exosomes released from prostate cancer cells can participate to weaken the ECM and induce angiogenesis. These exosomes contain miRNA-21-5p, miRNA-139-5p mediating the activation of MMP2,-9,-13 enzymes [80]. By administration of exosomal miRNA-92a derived from K562 cells, Umezu et al. elucidated that angiogenic potential of ECs such as immigration and tubulogenesis were enhanced [81]. Thereafter, contrariwise, miRNA-92a has been shown to have antiangiogenic roles. In this way, when it was secreted within MSCs-derived exosomes, it acts as an antiangiogenic factor [82]. Alike, the key role of miRNA-9 in angiogenesis is controversial. For example, exosome isolated from engineered nasopharyngeal carcinoma cells inhibits the angiogenic ability of endothelial cells by targeting MDK and PDK1/AKT pathways [83]. A work by Zhuang et al. showed that miRNA-9 has pro-angiogenic activity through reducing expression of SOCS5 gene and promoting the JAK-STAT axis function, which supports ECs migration and tumor angiogenesis [84]. In line with this, Qu et al. detailed that high level of miRNA-9 can differentiate MC3T3-E1 cells to osteoblast cells and increases angiogenesis via AMPK-dependent pathway [85]. Another potential role of exosomal miRNAs is immunosuppression by which reprogram the cells of the immune system, for instance, natural killer (NK) cells and dendritic cells (DCs) [86]. DCs, a key sub-population of immune cells, encourage immunity or make immune- tolerance according to the state of activation [87]. In this regard, Que. and co-workers demonstrated that exosomal miRNA-212-3p from pancreatic cancer cells degrades Regulatory factor X-associated protein (RFXAP) mRNAs in DCs, leading to immune tolerance through minimizing of MHC II molecules [86]. EVs miRNAs also play as a key regulator of NK cells. For example, MVs released from hypoxic tumor cells adversely affect NK cells function via delivering miRNA-23a and TGF- $\beta$ [88]. Interestingly, Yin et al. pointed out the exosomal miRNA-214 induces immunological tolerance response in $\mathrm{CD}^{+} \mathrm{T}$ cells. They also confirmed that tumor-induced immune tolerance was reversed when exosomes purified from human embryonic kidney cell line 293 (HEK293) delivered antisense copy of miRNA-214 to T helper cells [89]. Thus, preliminary data suggest that tumor-derived exosomal miRNAs participate to inducing tumor tolerance of the immune system. In conclusion, tumor-derived exosomes have pivotal roles in cancer progression; especially their miRNA cargoes contribute to manipulating transcriptome pool of target cells. It seems that discovery in the field of exosomal miRNAs biology could uncover the underlying mechanisms promoting the aggressive feature of tumors.

\section{Exosomal miRNAs as a tumor biomarker}

In the new global oncology, tumor-derived exosomes have become a central candidate for promoting tumor survival, invasion, metastasis, angiogenesis, and immunomodulation through transmitting onco-molecules including miR NAs, DNA, proteins, and lipids [67]. As miRNAs bearing exosomes can be distributed to bio-fluids, therefore, liquid-biopsy from urine, plasma, and CSF is a noninvasive method for obtaining exact information about tumor environment/status [63]. Firstly, Taylor and colleagues reported that serum biomarkers such as miRNA214, miRNA-205, miRNA-203, miRNA-141, miRNA-200 a,-b,-c, and miRNA-21 are also rich in sera-derived exosomes of patients suffering from ovarian tumors (Table 1) [102]. In lung adenocarcinoma patients, miRNAs analysis showed a significant correspondence between tumor cell miRNAs and circulatory exosomal miRNAs expression pattern. Thus, these miRNAs may be considered as a biomarker of lung cancer. Moreover, it was revealed that total exosomes and miRNAs were enhanced in patients in 
comparison to the healthy group [103]. Similarly, using wide-range microRNAs analysis, Cazzoli and et al. declared that the exosomal miRNAs including miRNA-2005p, miRNA-378a, miRNA-379, and miRNA139-5p could serve as biomarkers of lung adenocarcinoma [8]. In the context of breast tumors, biomarker application of exosomal miRNAs was assayed using cancerous cell lines including MCF-7 carcinoma cells and also MDA-MB-231 in vitro. For example, Kruger et al., discovered that MCF-7 cells release exosomes enriched with miRNAs such as miRNA494, miRNA-198, miRNA34a, and miRNA-26a, whereas exosomal miRNA-328-5p, miRNA-149-3p, and miRNA-130a were available in the epithelial cancerous cells; MDA-MB-231 cell line [104]. In triple negative breast malignancy individuals, circulatory levels of exosomal miRNA-373 are considerably up-regulated, thus it may be used as cancer biomarker [105]. Up-regulation of exosomal miRNA-19a in the bloodstream of colorectal cancer (CRC) subjects were recorded and interestingly introduced as a relapse biomarker of CRC [106]. Furthermore, the expression pattern of the exosomal miRNA-1792a family in the circulatory system was significantly correlated to the CRC relapse rate. In the last few years, some laboratories used urine exosomal miRNA as prostate and bladder cancers biomarkers, so that high level of exosomal miRNA-21 [92] and miRNA-21-5p [107] were considered as an indication of prostate and bladder cancer development respectively. We have shown in Table 1 exosomal miRNAs that may use as cancer diagnostic biomarkers in different cancers.

\section{Exosome-based miRNA delivery system}

A recent development in the cancer therapy led to design the miRNA therapy systems, which engage tumorsuppressor miRNAs for shrinkage tumor mass [108]. In this regard, exosomes as a bio-container of non-coding RNA are taken into consideration [109]. Recent reports have revealed that exosomal miRNAs are the imperative effectors of cells in the biological environment $[41,110]$. As miRNAs actively regulate cell function, it is sensible to recommend that engineered exosomal miRNAs are a useful tool in the management of diseases [111, 112]. Kosaka and coworkers showed that intra-tumor administration of miRNA-143-enriched conditioned medium $(\mathrm{CM})$ to $\mathrm{nu} / \mathrm{nu}$ mice with grafted prostate tumor caused the cancer cell shrinkage. Besides, the mRNA level of KRAS and ERK5 as target genes of miRNA-143 decreased following injection of miRNA-143- transduced CMs. Conversely, the growth rate of normal cells was not suppressed by exogenously-transduced miRNA-143. Thus, they concluded that exosome-based miRNAs therapy may serve as a specific tool without non-targeting effect [113]. Lou et al. found that MSCs-derived exosomes as miRNA-122 vehicle increase hepatocellular carcinoma chemosensitivity. In this vein, use of chemotherapeutic agents along with the delivery of miRNA122 via MSC-derived exosomes deeply caused fall in the cell cycle at G0/G1 level and increased cell apoptosis rate, what signifies a hopeful approach for hepatocellular carcinoma treatment [114]. Moreover, exosomes exogenously enriched with siRNAs to inhibit diseases, for example, it has recently been shown that exosomes purified from glioblastoma cells can uptake synthetic siRNAs targeting Huntingtin mRNA and proficiently carried siRNAs to mouse neurons to bock Huntingtin mRNAs [115]. Ohno and et al. loaded synthetic let-7a miRNAs into HEK293 cells to obtain exosomes encompassing those molecules, thereafter, these exosomes inhibited tumor mass growth in vivo [112]. These results indicate that exosome-based miRNA delivery potentially

Table 1 Possible exosomal miRNAs as tumor biomarker

\begin{tabular}{llll}
\hline Cancer & miRNAs considered as biomarkers & Source & Reference \\
\hline $\begin{array}{l}\text { Acute myeloid } \\
\text { leukemia }\end{array}$ & miR-150, miR-1246, miR-155 & Serum & [90] \\
Bladder & miR-15b, miR-24, miR-135b, miR-1224-3p & Urine & [91] \\
& miR-21, miR-4454 & Urine & [92] \\
Breast & miR-200a, miR-200c, miR-205 & Serum \\
& miR-10, miR-21, miR-182, miR-373, miR-1246 & Serum \\
Cervical & miR-21, miR-146a & Cervical lavages \\
Colorectal & miR-23a, miR-1229, miR-1246, miR-let-7a, miR-150, miR-21, miR-223 & Serum \\
& let7a, miR-21, miR-192, miR-221 & Serum \\
Esophageal & miRNA-21 & Serum \\
Glioma & miR-320, miR-574-3p & Serum \\
& miR-21 & CSF \\
Lung & miR-155,miR-17-3p, miR-205, miR-21, miR-106a, miR-146, miR-191, miR-192, miR-212, miR- & Plasma and \\
& 214 miR-203, miR-210 & Bronchoalveolar \\
\hline
\end{tabular}


contributes to tumor regression. However, extra inquiries are essential to uncover fundamental mechanisms related to miRNA signaling pathways in the target cells. Overall, it seems that miRNA therapy is at its infancy and there are still certain limitations regarding miRNA encapsulation into exosomes, the safety of exosomes, and also unwanted results in recipient cells. It is encouraging to declare that there is increasing interest in preclinical and clinical applications of miRNAs in specific cancers. By May 2019, the clinical trial data-collection https://clinicaltrials.gov prepared about 52 clinical trials to deal with miRNA ventures (Table 2 and Fig. 2). Scrutiny on the recorded experiments unveiled that the major part of clinical trials belongs to breast cancer diseases (roundly 19.25\%). In addition, a study related to using of exosomal miRNAs in prostate cancer patients was recorded by identified number NCT02366494. Taken together, these findings suggest the fact that miRNAs are a new and applicable tool in a clinical situation.

\section{Exosomes as a drug delivery vehicle}

Recently, the approach of nanotechnology has attracted the attention of researchers to the use of pharmacology in medicine. The main purpose of nanoparticle technologies in drug delivery system is the improvement of the efficacy and specificity of therapeutic agents as well as the reduction of their toxicity in the body [116]. In the field of cancer therapy, nanoparticles-based drug delivery system has been approved by the USA Food and Drug Administration (FDA). For example, Doxil ${ }^{\circ}$ (encapsulated doxorubicin (Dox) into the liposomes) [117] and Abraxane $^{\bullet}$ (paclitaxel (PTX) attached to nanoparticles) are available to use [118]. Interestingly, there is an excessive interest in the use of biological carriers in drug delivery systems that successfully act as a channel to deliver drugs to the target sites. One of these successful candidates is exosome [119]. Exosomes represent one of the major paracrine signaling modules between cells with roles in physiological and pathological conditions, ranging from the normal cell homeostasis to the tumor cells metastasis [120]. A growing number of studies have found that EVs especially exosomes obtained from eligible stem cells can be involved in the treatment of various diseases. For example, the authors showed that exosomes derived from MSCs elicit beneficial effects in disease models [121, 122]. However, several attempts have been made to use purposefully engineered exosomes instead of using unsought exosomes [123]. Thereby, exosomes have attracted scientific attention, because these particles can encapsulate therapeutic agent and efficiently deliver it to target cells [18]. Furthermore, they represent a range of beneficial features such as safety and low immunity, regulating cell signaling, desirable negative zeta potential, the capacity of transferring large amounts of biomolecules, and ability to be engineered for the treatment of various diseases $[16,124]$. Furthermore, they can specifically deliver their cargoes to the distantly target sites, even they pass through the blood-brain barrier [16] In this regard, laboratories have examined the possible therapeutic potential of exosomes via sorting RNAs and therapeutic compounds into exosomes in vitro and in pre-clinical experiments. Of note, the exosome-based delivery system has generally designed following two protocols (Fig. 3); I: direct engineering method, by which isolated exosomes directly modified to artificial exosomes and II: indirect engineering method, by which parental cells targeted to modification. According to the clinical trial database (http://clinicaltrials.gov) up to May 2019, when using exosome as a keyword, there are 99 studies about exosomes. To date, only a few exosome-based deliveries clinical trials are listed, therefore, we can point a study in phase I which designed to investigate the delivery of curcumin to colon cancer tissue by plant-derived exosomes (NCT number: 0124072). Additionally, two clinical trials in phase II and I (NCT number: 01159288, NCT number: 03608631) are presented where researchers will engage artificial exosomes against lung and pancreases cancers. In this section, we review exosome engineering methodology and summarize results of exosome therapy in experiments.

\section{Direct engineering method}

Direct engineering method is a promising strategy to load pre-isolated exosomes with therapeutic agents for instance drugs, synthetic compounds, and biomolecules (Fig. 3). Several techniques have been utilized for loading exosome such as simple incubation, electroporation, sonication, extrusion, freeze/thaw cycle, and sponinassisted methods that summarized in Table 3. In this section, we describe the potential agents directly loaded into exosomes by the different strategies. Recent evidence suggests that exosomes can uptake exogenous compounds in vitro. For example, Zhuang et al. designed an experiment where curcumin incubated with tumor cell-derived exosomes. Consequently, exosomes successfully encapsulated curcumin and delivered it to microglia cells via an intranasal way in a brain inflammatory model. Furthermore, authors successfully encapsulated Stat3 inhibitor into those exosomes [125]. Similarly, curcumin potentially was directed into EL-4 (mouse lymphoma cell line)-derived exosomes, and it has been reported that the efficacy of curcumin was increased by delivering exosomes to inflammatory cells [126]. Using the extrusion method, Fuhrmann and coworkers showed that porphyrins easily were loaded into exosomes collected from different stem cells. Authors demonstrated that artificial exosomes produced by the extrusion 
Table 2 The list of miRNAs related clinical trials documented up to May 2019

\begin{tabular}{|c|c|c|c|}
\hline Condition or disease & Type of miRNA & Phase & NCT number \\
\hline \multirow[t]{10}{*}{ Breast Cancer } & Total & Phase-II & NCT02127073 \\
\hline & Total & Phase-IV & NCT01612871 \\
\hline & Total & ND & NCT03779022 \\
\hline & Total & ND & NCT01598285 \\
\hline & Total & ND & NCT02656589 \\
\hline & Total & ND & NCT02065908 \\
\hline & Total & ND & NCT01231386 \\
\hline & Total & ND & NCT01722851 \\
\hline & Total & ND & NCT01957332 \\
\hline & Total & ND & NCT02950207 \\
\hline \multirow[t]{3}{*}{ Prostate Cancer } & Total & ND & NCT01220427 \\
\hline & Total & ND & NCT02366494 \\
\hline & Total & ND & NCT02964351 \\
\hline \multirow[t]{3}{*}{ Pancreatic Cancer } & Total & Phase-II & NCT02634502 \\
\hline & Total & ND & NCT02531607 \\
\hline & $\operatorname{miR}-25$ & ND & NCT03432624 \\
\hline \multirow[t]{4}{*}{ Colorectal Cancer } & miR-31-3p and miR-31-5p & Phase-III & NCT03362684 \\
\hline & total & ND & NCT03309722 \\
\hline & Total & ND & NCT02876133 \\
\hline & Total & ND & NCT01712958 \\
\hline Bladder Cancer & miR-155 & ND & NCT03591367 \\
\hline \multirow[t]{2}{*}{ Esophageal Cancer } & Total & Phase-II & NCT02392377 \\
\hline & Total & ND & NCT02812680 \\
\hline \multirow[t]{4}{*}{ Lung Cancer } & Total & ND & NCT02247453 \\
\hline & Total & ND & NCT03452514 \\
\hline & Total & ND & NCT03397355 \\
\hline & Total & ND & NCT03293433 \\
\hline \multirow[t]{2}{*}{ Thyroid Cancer } & Total & ND & NCT01964508 \\
\hline & Total & ND & NCT01433809 \\
\hline \multirow[t]{2}{*}{ Brain Tumors } & Total & ND & NCT03630861 \\
\hline & Total & ND & NCT01595126 \\
\hline \multirow[t]{3}{*}{ Oral Cancer } & miR-21 and miR-200 & Phase-III & NCT03685409 \\
\hline & Total & Phase-IV & NCT03684707 \\
\hline & microRNA-29b & ND & NCT02009852 \\
\hline \multirow[t]{3}{*}{ Skin Cancer } & Total & ND & NCT00849914 \\
\hline & Total & ND & NCT01143311 \\
\hline & Total & ND & NCT01345760 \\
\hline Kidney Cancer & Total & ND & NCT00806650 \\
\hline Endometrial Cancer & Total & ND & NCT01119573 \\
\hline \multirow[t]{2}{*}{ Ovarian Cancer } & Total & ND & NCT02758652 \\
\hline & Total & ND & NCT03738319 \\
\hline Cancer of Head and Neck & microRNA-29 family & ND & NCT01927354 \\
\hline \multirow[t]{2}{*}{ Leukemia } & Total & ND & NCT01505699 \\
\hline & microRNA-34a and & ND & NCT01057199 \\
\hline
\end{tabular}


Table 2 The list of miRNAs related clinical trials documented up to May 2019 (Continued)

\begin{tabular}{llll}
\hline Condition or disease & Type of miRNA & Phase & NCT number \\
\hline & microRNA-194 & ND & NDCT01229124 \\
& Total & NCT01511575 \\
& Total & ND & NCT00896766 \\
Liver & Total & ND & NCT02448056 \\
& Total & ND & NCT03227510 \\
& Total & ND & NCT02928627 \\
& miR-221 and miR-222 & ND & NCT01247506 \\
& Total & &
\end{tabular}

ND Not Determined

method show significant anticancer property compared with exosomes prepared via a passive method (incubation) [127]. Researchers also examined the encapsulation of chemotherapy drugs into exosomes. For instance, it has been shown that exosomes isolated from mouse immature DCs are capable of loading chemotherapeutics drugs like Dox by electroporation technique, and they specifically deliver the drug to the tumor tissue in BALB/c nude mice [19]. The ability of PTX to occupy exosome lumen confirmed by Kim et al. experiment in which PTX loaded into macrophages-derived exosomes by sonication method; resulted in amplified cytotoxicity response in the drug-resistant cancer cells [128]. Researchers have also attempted to encapsulate biomolecules into isolated exosomes. For instance, Alvarez-Erviti and colleagues showed that exosomes encapsulated exogenous siRNAs into their lumen via electroporation method. Additionally, the authors reported that these exosomes intravenously delivered siRNAs to neuron and glial cells in the brain and led to gene inhibition [129]. Thereafter, recent studies have found that exogenous siRNAs could be internalized into exosomes in different ways and may cause gene knockdown in target cells $[130,131]$. It has recently been shown that glioblastomaderived exosomes successfully uptake modified siRNAs targeting Huntingtin mRNA and efficiently delivered siRNAs to mouse neurons and led to silence Huntingtin mRNAs [115]. Similarly, in a recent work, using sonication or electroporation, purified exosomes from HEK293 and MCF-7 cells encompassed exogenous siRNAs, miRNA, and single-stranded DNA (ssDNA) oligonucleotides. These exosomes have been confirmed that

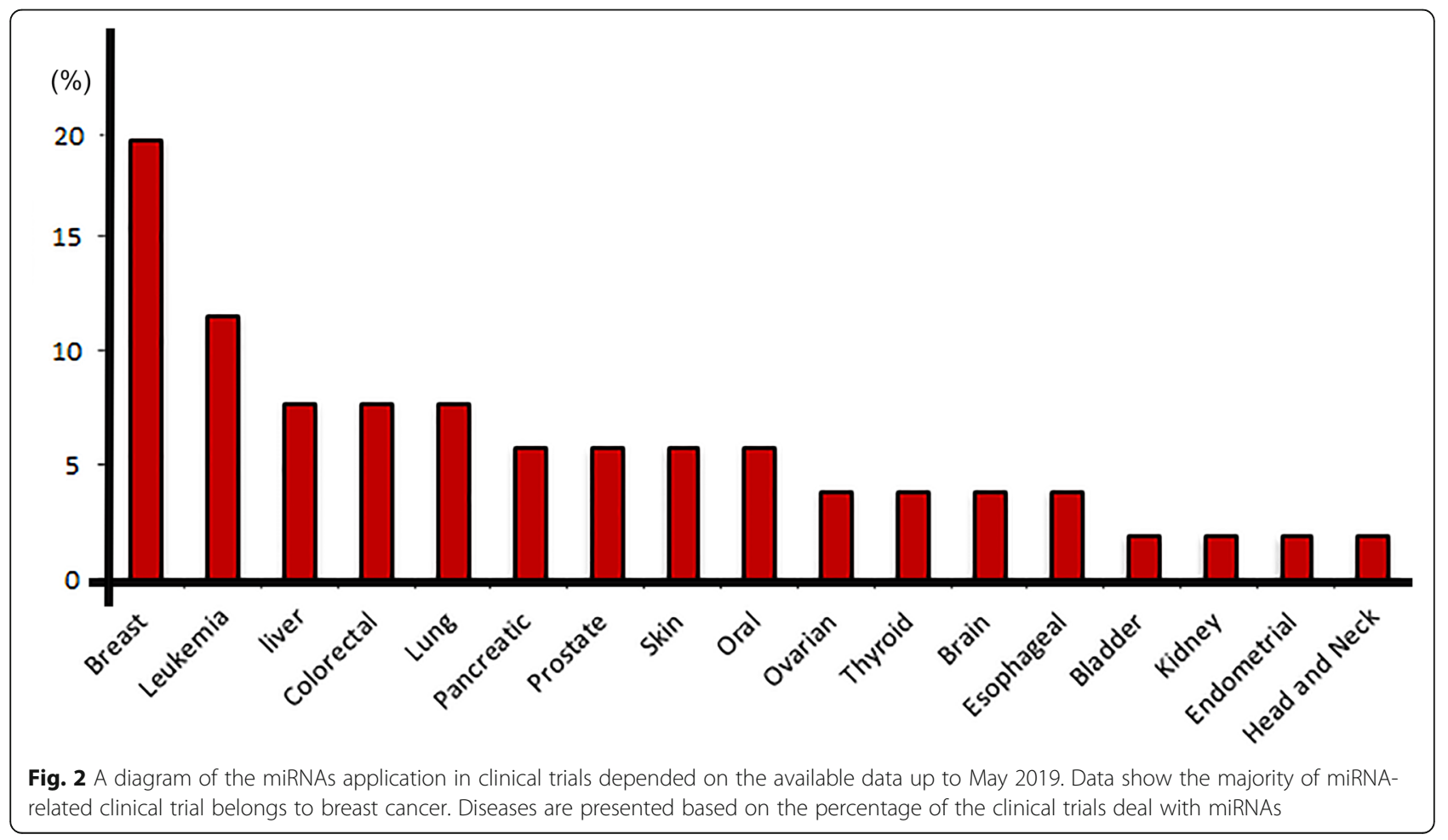




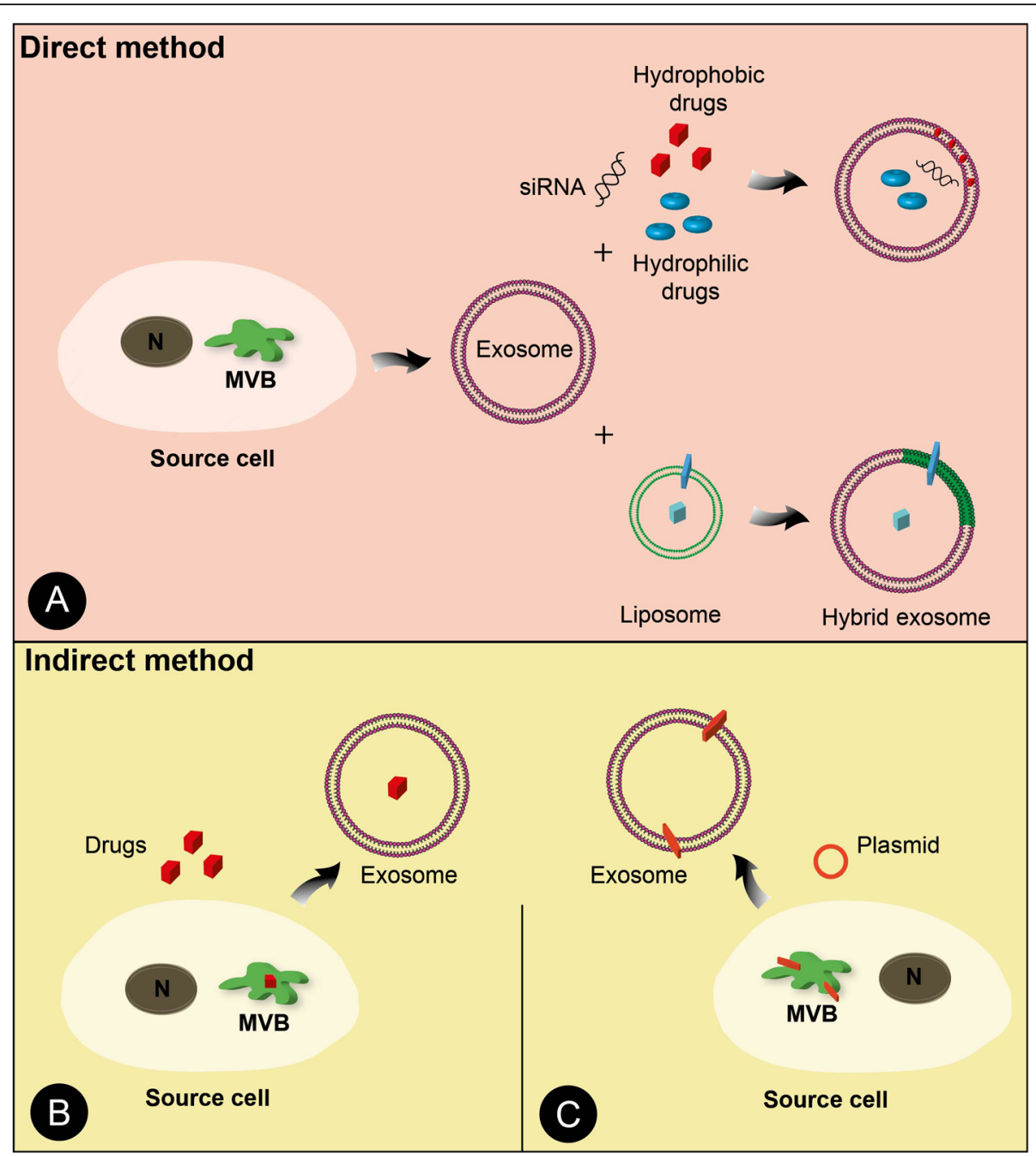

Fig. 3 Categories of different methods used to design exosome-based delivery system. In the direct method different compounds such as hydrophilic or hydrophobic drugs and also siRNAs are added to purified exosomes suspension, subsequently, exosomes encompass those compounds. In addition, liposome carrying drugs can be used to construct optional exosome-liposome hybrid vesicles (a). In the indirect method parental cells are modified to produce artificial exosomes. In this way, cells co-cultured with different therapeutic agents (b) or by using a vector, manipulated to express optional cargoes in exosomes (c)

Table 3 Comparison of the methods utilized for loading of therapeutic agents into exosomes

\begin{tabular}{|c|c|c|c|}
\hline Methods & Therapeutic agents & Advantage & limits \\
\hline Incubation & $\begin{array}{l}\text { Paclitaxel/Curcumin, siRNAs, Porphyrins, } \\
\text { Catalase, Doxirubicin }\end{array}$ & simple & $\begin{array}{l}\text { Low loading efficiency Drugs } \\
\text { may harm cells }\end{array}$ \\
\hline Electroporation & Doxirubicin, siRNAs, linear DNA, Catalase & $\begin{array}{l}\text { large molecules } \\
\text { can be loaded }\end{array}$ & $\begin{array}{l}\text { Low loading efficiency, Interrupts } \\
\text { exosome integrity, siRNA clump }\end{array}$ \\
\hline Extrusion & Porphyrins, Catalase & High drug loading efficiency & Alternations in membrane \\
\hline Sonication & Paclitaxel, siRNAs, Catalase, & $\begin{array}{l}\text { High drug loading efficiency, } \\
\text { Suitable for small RNAs }\end{array}$ & $\begin{array}{l}\text { Alternations in membrane Not suitable } \\
\text { for hydrophobic agents }\end{array}$ \\
\hline Freeze/thaw & Catalase, DOX & $\begin{array}{l}\text { Potential of } \\
\text { membranes fusion }\end{array}$ & $\begin{array}{l}\text { Low loading Efficiency } \\
\text { Cramped exosomes }\end{array}$ \\
\hline Saponin-assisted & Catalase, Porphyrins, DOX & $\begin{array}{l}\text { Relative high drug } \\
\text { loading efficiency }\end{array}$ & Toxicity and harmful effects long protocol \\
\hline
\end{tabular}


induced anticancer characteristics through silencing HER2 genes [132]. Another interesting study evaluated the capacity loading of DNA molecules into exosomes. Lamichhane et al. used electroporation method that linear DNA was sorted into exosomes. They also revealed that there is a direct relationship between DNA loading efficiency and size of linear DNA molecules [133]. Haney et al. conducted an interesting experiment where attempted to load catalase into exosome ex vivo. Using exosomes from macrophages, authors tested the efficacy of different loading strategies such as incubation, extrusion, freeze/thaw cycle, sonication, and even saponin-assisted to sort catalase into exosome. Exosomes from diverse source differently encapsulated catalase and efficiently delivered it to neuronal cells in vitro and into the brain of Parkinson's disease mouse model and showed considerable neuroprotective effects [134]. Other compounds such as dextran molecules were successfully loaded into exosomes [135]. Collectively, the direct engineering method seems to be a promising strategy to sort specific compound into exosomes. In addition, however, further studies are necessary to elucidate which loading method has high efficacy and acts inclusively at the same time.

\section{Indirect engineering method Drug loading}

In this protocol, therapeutic agents such as drugs exogenously packed into parental cells (Fig. 3). In the case of drug loading techniques, cells are incubated with drugs in vitro, and after the incubation period, purified exosomes can be subjected to down-stream studies (Fig. 3). Pioneering research by LV et al. examined the effect of anticancer drugs on exosomal HSPs protein loading potential in hepatocellular carcinoma cells (HepG2) in vitro. Authors showed that anticancer drugs simultaneously increased exosome secretion and altered HSPs content in isolated exosomes. Interestingly, these exosomes powerfully motivated NK cells cytotoxicity, therefore induced immunogenicity responses in NK cells [136]. It has been proven that PTX, an anticancer chemotherapy drug when co-cultured with MSCs over $24 \mathrm{~h}$; it could enter into EVs. Interestingly, PTX-bearing EVs exhibited more anticancer effect in comparison with EVs derived from the control group [137]. In addition, the liposome-mediated method was also used to construct artificial EVs, that using this method hydrophobic compounds filled into EVs [138]. In line with this, a similar work showed that lipophilic and hydrophilic drugs could be cosorted powerfully into the purified EVs when their parental cells treated with membrane fusogenic liposomes containing those drugs [139].

\section{Parental cell modification}

One of the exciting methods is the genetically manipulating of parental cells to produce artificial exosomes
(Fig. 3). In this manner, there is an interesting approach to using the exosome membrane as a therapeutic tool. Indeed exosome surface molecules engineered to enhance efficiency and sensitivity of the exosome-based delivery system [19]. Besides this, parental cells engineered to generate optional exosomes containing specific biomolecules for deliver cargoes to target cells; in fact, exosomes designed to carry specific molecules. According to this statement, DCs were transfected to over-express Lamp2b, located in the exosomal membrane, and combined to the neural RVG peptide to produce optional exosomes with a modified membrane which bind specifically to neuron cells in Alzheimer's disease mouse model [129]. In a study which set out to modify exosomes membrane, Liu et al. found that cells over-expressing of RVG-Lamp2b peptide produced exosomes containing RVG-Lamp2b peptide on the membrane surface. These exosomes specifically delivered opioid receptor mu (MOR) siRNA to the mouse brain and Neuro2A cells in vitro. Of note, concurrently, the MOR siRNA oligonucleotides transfected to cells to produce exosomes bearing those siRNAs [140]. Ohno and et al. designed a wonderful experiment by which HEK293 modified to over-express GE11 or EGF molecules. They collected exosomes from CM and confirmed the expression of GE11 or EGF proteins on the exosome membrane. After that, the delivery capacity of exosomes in an in vitro and also in xenograft breast cancer tissue in RAG2-/- model was proved. Simultaneously, they showed that exosomes were strongly trapped in an EGFR dependent manner and synthetic let-7a miRNAs subjected to tumor mass in vivo [112]. Authors indicated that artificial exosomes are capable of delivering therapeutic agents to EGFR-expressing tumors. As mentioned above; some scientists manipulated stem cells to produce exosomes with optional cargoes for the treatment of diseases. For instance, Gnecchi and colleagues showed that CM from MSCs -Akt-overexpressing strongly improved cardiac function in an infarcted mouse model [141]. Furthermore, U87MG glioblastoma cells were manipulated to become overexpressing- Delta-like 4 (Dll4) cells which abundantly produced exosomes-bearing DII4. Purified exosomes-bearing DII4 efficiently were capable of increasing angiogenesis both in vitro and in vivo models [142]. It was shown that exosomes from human CD34 ${ }^{+}$ Shh-overexpressing cells transfer Shh molecules to ischemic myocardium and stimulate the Shh signaling pathway in target cells [143]. In a murine collagen-induced arthritis experiment, DCs were genetically transfected with indoleamine 2, 3-dioxygenase (IDO) to produce optional exosomes. Authors declared that exosomes carrying IDO exhibit immunosuppressive and anti-inflammatory effect and inhibit arthritis [144]. In a study, THP-1 macrophages transfected with anti-oncomirs such as miR-143 that cells successfully exported miR-143 molecules associated with 
exosomes. These exosomes exhibited antitumor effects [145]. Furthermore, there has been an interest in a method by which stem cells are being activated to produce functional secretomes. For instance, Salomon et al. cultured umbilical derived MSCs under hypoxia and examined the angiogenic potential of their exosomes in vitro. The result showed that oxygen stress elevated exosome secretion rate and hypoxic exosomes significantly encouraged angiogenesis [146]. In a similar vein, exosomes derived from a hypoxic human leukemia cell line (K562) profoundly increased angiogenesis in endothelial cells compared to exosomes from normoxic k562 cells. Further scrutiny revealed that hypoxic exosomes abundantly contain miRNA-210 which target angiogenesis signaling pathway [147]. Angiogenic potential of exosomes isolated from activated THP-1, a human monocyte cell line, has also been observed. THP-1 cell line was activated by different inflammatory factors which resulted in an increased level of miRNA-150 in exosomes, subsequently, exosomes enhanced endothelial cell migration [110]. Despite the few studies, these experiments offered thus far present evidence that parental cell activation may be a useful strategy to produce functional exosomes.

\section{Conclusion}

In recent years, the significance of exosomes as intercellular mediators has been described. Tumoral exosomes by transferring miRNAs play pivotal roles in tumor maintenance. As tumoral exosomes contain tumor information and also available in almost bio-fluids, exosomes can provide a novel approach in early diagnosis of cancers and serve as a tumor biomarker. In addition, modification of exosomes may able researchers to deliver tumor-suppressive miRNAs to tumor cells. However, this is required to determine exactly how miRNA were encapsulated into exosomes and which miRNAs are suitable to use as a tumor inhibitor and cancer biomarker. In general, the exosome-based delivery vehicle represents an efficient system by which a large number of materials can be purposely delivered to target sites in the body. The advent of safe nano-carriers with high efficacy is the main goal of nano-medicine. Thus, the advance of artificial exosomes has opened a hopeful opportunity for the delivery of therapeutic agents. Nonetheless, future studies on the present issue are therefore recommended answering some questions; which cells should be manipulated to produce optional exosomes? In another word, which exosomes are safe and bio-compatible for drug delivery system? And, What is the suitable and nontoxic method for the modification of exosomes? In addition, the majority of experiments are carried out in vitro and ultimately in vivo models, therefore, the safety, specificity, and efficiency of this system in clinical trials remains still more elusive.

\section{Abbreviations}

ABs: Apoptotic Bodies; Ago2: Argonaute2; CM: Conditioned Medium CRC: colorectal cancer; DCs: Dendritic Cells; DIl4: Delta-like 4; Dox: Doxorubicin;
ECM: Extracellular Matrix; ECs: Endothelial Cells; ESCRT: Endosomal Sorting Complex Required For Transport; EVs: Extracellular Vesicles; FDA: USA Food and Drug Administration; HEK293: Human Embryonic Kidney Cell Line 293; HepG2: Hepatocellular Carcinoma Cells; HuR: Human Antigen R; ICAM-

1: Adhesion Molecule 1; IDO: Indoleamine 2,3-dioxygenase; ISEV: International Society for Extracellular Vesicles; miRNAs: MicroRNAs; MMPs: Matrix metalloproteinase; MOR: Opioid Receptor Mu; MSCs: Mesenchymal Stem Cells; MVBs: Multivesicular Bodies; nSMase2: Sphingomyelinase 2; PM: Plasma Membrane; PTX: Paclitaxel; RBPs: RNA-binding proteins; RFXAP: Regulatory factor X-associated protein; RLC: RISC-Loading Complex; rRNA: Ribosomal RNA; SNAREs: Soluble NSF attachment protein receptors; ssDNA: Singlestranded DNA; TRL: Toll-like Receptors; TSAP6: Tumor suppressor activated pathway 6

\section{Acknowledgements}

We gratefully thank Dr. Muhammad Nawaz (Department of Rheumatology and Inflammation Research (DRIR), Göteborg, Sweden) for fruitful comments and critically reading the manuscript.

\section{Authors' contributions}

$J R$, and RR, edited the manuscript and with equal conceptualization. NJ, NAS, RA, LS, SAK, MF, TE, EA, and MM collected data and wrote manuscript. All authors read and approved the final manuscript.

\section{Authors' information}

Dr. J. R., Dr. N. J., Dr. R. A., and Dr. R. R. are faculty membranes of Urmia University of Medical Sciences and Tabriz University of Medical Sciences, Iran. N. A.S., L. S., S. A. K., M. F., T. E., E. A., and M. M. are student in medical sciences (including Biotechnology, Biochemistry, Laboratory Sciences, Medical Physics, Physiology, Genetics, Parasitology) at Urmia University of Medical Sciences, Tabriz University of Medical Sciences, and Arak University, Iran.

\section{Funding}

Not applicable

Availability of data and materials

Not applicable

Ethics approval and consent to participate

Not applicable

\section{Consent for publication}

Not applicable

\section{Competing interests}

The authors declare that they have no competing interests

\section{Author details}

${ }^{1}$ Stem Cell Research Center, Tabriz University of Medical Sciences, Tabriz, Iran. ${ }^{2}$ Department of Applied Cell Sciences, Faculty of Advanced Medical Sciences, Tabriz University of Medical Sciences, Tabriz, Iran. ${ }^{3}$ Solid Tumor Research Center, Cellular and Molecular Medicine Institute, Urmia University of Medical Sciences, Shafa St, Ershad Blvd., P.O. BoX: 1138, Urmia 57147, Iran.

${ }^{4}$ Department of Medical Physics and Imaging, Urmia University of Medical Sciences, Urmia, Iran. ${ }^{5}$ Department of Oncology, Imam Khomeini hospital, Urmia University of Medical Sciences, Urmia, Iran. ${ }^{6}$ Department of Medical Laboratory Sciences, Imam Khomeini hospital, Urmia University of Medical Sciences, Urmia, Iran. ${ }^{7}$ Department of biology, faculty of sciences, Arak University, Arak, Iran. ${ }^{8}$ Department of Genetic, Urmia University of Medical Sciences, Urmia, Iran. ${ }^{9}$ Department of Medical Parasitology, Urmia University of Medical Sciences, Urmia, Iran.

Received: 23 May 2019 Accepted: 4 July 2019

Published online: 10 July 2019

\section{References}

1. Siegel RL, Miller KD, Jemal A. Cancer statistics, 2017. CA: Cancer J Clin. 2017;67:7-30. 
2. Kamińska K, Szczylik C, Bielecka ZF, Bartnik E, Porta C, Lian F, Czarnecka AM. The role of the cell-cell interactions in cancer progression. JCMM. 2015;19:283-96.

3. Schiffman JD, Fisher PG, Gibbs P. Early detection of cancer: past, present, and future. Am Soc Clin Oncol Educ Book. 2015;35:57-65.

4. Shyamala K, Girish H, Murgod S. Risk of tumor cell seeding through biopsy and aspiration cytology. J Int Soc Prev Community Dent. 2014;4:5.

5. Crowley E, Di Nicolantonio F, Loupakis F, Bardelli A. Liquid biopsy: monitoring cancer-genetics in the blood. Nat Rev Clin Oncol. 2013;10:472.

6. Skog J, Würdinger T, Van Rijn S, Meijer DH, Gainche L, Curry WT Jr, Carter BS, Krichevsky AM, Breakefield XO. Glioblastoma microvesicles transport RNA and proteins that promote tumour growth and provide diagnostic biomarkers. Nat Cell Biol. 2008;10:1470.

7. Fatima F, Nawaz M. Vesiculated long non-coding RNAs: offshore packages deciphering trans-regulation between cells, cancer progression and resistance to therapies. Noncoding RNA. 2017;3:10.

8. Cazzoli R, Buttitta F, Di Nicola M, Malatesta S, Marchetti A, Rom WN, Pass HI. microRNAs derived from circulating exosomes as noninvasive biomarkers for screening and diagnosing lung cancer. J Thorac Oncol. 2013:8:1156-62.

9. Nawaz M, Camussi G, Valadi H, Nazarenko I, Ekström K, Wang X, Principe S, Shah N, Ashraf NM, Fatima F. The emerging role of extracellular vesicles as biomarkers for urogenital cancers. Nat Rev Urol. 2014;11:688.

10. Nawaz M, Fatima F, Nazarenko I, Ekström K, Murtaza I, Anees M, Sultan A, Neder L, Camussi G, Valadi H. Extracellular vesicles in ovarian cancer: applications to tumor biology, immunotherapy and biomarker discovery. Expert Rev Proteomics. 2016;13:395-409.

11. Mateescu B, Kowal EJ, Van Balkom BW, Bartel S, Bhattacharyya SN, Buzás El, Buck AH, De Candia P, Chow FW, Das S. Obstacles and opportunities in the functional analysis of extracellular vesicle RNA-an ISEV position paper. J Extracell Vesicles. 2017;6:1286095

12. Raposo G, Stoorvogel W. Extracellular vesicles: exosomes, microvesicles, and friends. J Cell Biol. 2013;200:373-83.

13. Colombo M, Moita C, van Niel G, Kowal J, Vigneron J, Benaroch P, Manel N, Moita LF, Théry C, Raposo G. Analysis of ESCRT functions in exosome biogenesis, composition and secretion highlights the heterogeneity of extracellular vesicles. J Cell Sci. 2013. https://doi.org/10.1242/jcs.12886.

14. Taylor DD, Zacharias W, Gercel-Taylor C. Exosome isolation for proteomic analyses and RNA profiling. Serum/Plasma Proteomics. New York: Humana Press. Methods Mol Biol. 2011;728:235-46.

15. Romagnoli GG, Zelante BB, Toniolo PA, Migliori IK, Barbuto JAM. Dendritic cell-derived exosomes may be a tool for cancer immunotherapy by converting tumor cells into immunogenic targets. Front Immunol. 2015;5: 692.

16. Malhotra H, Sheokand N, Kumar S, Chauhan AS, Kumar M, Jakhar P, Boradia VM, Raje Cl, Raje M. Exosomes: tunable nano vehicles for macromolecular delivery of transferrin and lactoferrin to specific intracellular compartment. J Biomed Nanotechnol. 2016;12:1101-14.

17. Mathiyalagan P, Sahoo S. Exosomes-based gene therapy for microRNA delivery. New York: Humana Press. Methods Mol Biol. 2017;1521:139-52.

18. Pegtel DM, Cosmopoulos K, Thorley-Lawson DA, van Eijndhoven MA, Hopmans ES, Lindenberg JL, de Gruijl TD, Würdinger T, Middeldorp JM. Functional delivery of viral miRNAs via exosomes. Proc Natl Acad Sci U S A. 2010;107:6328-33.

19. Tian Y, Li S, Song J, Ji T, Zhu M, Anderson GJ, Wei J, Nie G. A doxorubicin delivery platform using engineered natural membrane vesicle exosomes for targeted tumor therapy. Biomaterials. 2014;35:2383-90.

20. Ostrowski M, Carmo NB, Krumeich S, Fanget I, Raposo G, Savina A, Moita CF, Schauer K, Hume AN, Freitas RP. Rab27a and Rab27b control different steps of the exosome secretion pathway. Nat Cell Biol. 2010;12:19.

21. György B, Szabó TG, Pásztói M, Pál Z, Misják P, Aradi B, László V, Pállinger $E_{\text {, }}$ Pap E, Kittel A. Membrane vesicles, current state-of-the-art: emerging role of extracellular vesicles. Cell Mol Life Sci. 2011;68:2667-88.

22. Kowal J, Tkach M, Thery C. Biogenesis and secretion of exosomes. Curr Opin Cell Biol. 2014;29:116-25

23. Théry C, Amigorena S, Raposo G, Clayton A. Isolation and characterization of exosomes from cell culture supernatants and biological fluids. Curr Protoc Mol Biol. 2006:30:3.22.1-3.22.29.

24. Willms E, Johansson HJ, Mäger I, Lee Y, Blomberg KEM, Sadik M, Alaarg A, Smith CE, Lehtiö J, Andaloussi SE. Cells release subpopulations of exosomes with distinct molecular and biological properties. Sci Rep. 2016;6:22519.
25. Yu X, Harris SL, Levine AJ. The regulation of exosome secretion: a novel function of the p53 protein. Cancer Res. 2006;66:4795-801.

26. Bobrie A, Colombo M, Raposo G, Théry C. Exosome secretion: molecular mechanisms and roles in immune responses. Traffic. 2011;12:1659-68.

27. Record M, Subra C, Silvente-Poirot S, Poirot M. Exosomes as intercellular signalosomes and pharmacological effectors. Biochem Pharmacol. 2011;81: 1171-82.

28. Ludwig A-K, Giebel B. Exosomes: small vesicles participating in intercellular communication. Int J Biochem Cell Biol. 2012;44:11-5.

29. Savina A, Fader CM, Damiani MT, Colombo MI. Rab11 promotes docking and fusion of multivesicular bodies in a calcium-dependent manner. Traffic. 2005;6:131-43.

30. Wajant H, Moosmayer D, Wüest T, Bartke T, Gerlach E, Schönherr U, Peters N, Scheurich P, Pfizenmaier K. Differential activation of TRAlL-R1 and-2 by soluble and membrane TRAIL allows selective surface antigen-directed activation of TRAIL-R2 by a soluble TRAIL derivative. Oncogene. 2001;20:4101.

31. Muralidharan-Chari V, Clancy JW, Sedgwick A, D'Souza-Schorey C. Microvesicles: mediators of extracellular communication during cancer progression. J Cell Sci. 2010;123:1603-11.

32. Cocucci E, Racchetti G, Meldolesi J. Shedding microvesicles: artefacts no more. Trends Cell Biol. 2009:19:43-51.

33. Saha S, Woodbine L, Haines J, Coster M, Ricket N, Barazzuol L, Ainsbury E, Sienkiewicz Z, Jeggo P. Increased apoptosis and DNA double-strand breaks in the embryonic mouse brain in response to very low-dose $X$-rays but not $50 \mathrm{~Hz}$ magnetic fields. J Royal Soc Interface. 2014;11:20140783.

34. Sebbagh M, Renvoizé C, Hamelin J, Riché N, Bertoglio J, Bréard J. Caspase-3mediated cleavage of ROCK I induces MLC phosphorylation and apoptotic membrane blebbing. Nat Cell Biol. 2001;3:346.

35. Zhang D, Zhou T, He F, Rong Y, Lee SH, Wu S, Zuo L. Reactive oxygen species formation and bystander effects in gradient irradiation on human breast cancer cells. Oncotarget. 2016;7:41622

36. van Balkom BW, Gremmels H, Giebel B, Lim SK. Proteomic signature of mesenchymal stromal cell-derived small extracellular vesicles. Proteomics. 2019:19:1800163.

37. Schey KL, Luther JM, Rose KL. Proteomics characterization of exosome cargo. Methods. 2015;87:75-82

38. Vlassov AV, Magdaleno S, Setterquist R, Conrad R. Exosomes: current knowledge of their composition, biological functions, and diagnostic and therapeutic potentials. Bba-Gen Subjects. 1820;2012:940-8.

39. Bebelman MP, Smit MJ, Pegtel DM, Baglio SR. Biogenesis and function of extracellular vesicles in cancer. Pharmacol Ther. 2018;188:1-11.

40. Schorey JS, Bhatnagar S. Exosome function: from tumor immunology to pathogen biology. Traffic. 2008;9:871-81

41. Valadi H, Ekström K, Bossios A, Sjöstrand M, Lee JJ, Lötvall JO. Exosomemediated transfer of mRNAs and microRNAs is a novel mechanism of genetic exchange between cells. Nat Cell Biol. 2007:9:654.

42. Abels ER, Breakefield XO. Introduction to extracellular vesicles: biogenesis, RNA cargo selection, content, release, and uptake: Springer. Cell Mol Neurobiol. 2016;36:301-12

43. Batagov AO, Kuznetsov VA, Kurochkin IV. Identification of nucleotide patterns enriched in secreted RNAs as putative cis-acting elements targeting them to exosome nano-vesicles. BMC Genomics. 2011:12:S18.

44. Nedaeinia R, Manian M, Jazayeri M, Ranjbar M, Salehi R, Sharifi M, Mohaghegh F, Goli M, Jahednia S, Avan A. Circulating exosomes and exosomal microRNAs as biomarkers in gastrointestinal cancer. Cancer Gene Ther. 2017;24:48.

45. Jelonek $\mathrm{K}$, Widlak $\mathrm{P}$, Pietrowska $\mathrm{M}$. The influence of ionizing radiation on exosome composition, secretion and intercellular communication. Protein Pept Lett. 2016;23:656-63.

46. King HW, Michael MZ, Gleadle JM. Hypoxic enhancement of exosome release by breast cancer cells. BMC Cancer. 2012;12:421.

47. Liu T, Zhang Q, Zhang J, Li C, Miao Y-R, Lei Q, Li Q, Guo A-Y. EVmiRNA: a database of miRNA profiling in extracellular vesicles. Nucleic Acids Res. 2018;47: D89-93.

48. Bruschi M, Ravera S, Santucci L, Candiano G, Bartolucci M, Calzia D, Lavarello C, Inglese E, Petretto A, Ghiggeri G. The human urinary exosome as a potential metabolic effector cargo. Expert Rev Proteomics. 2015;12:425-32.

49. Pathan M, Fonseka P, Chitti SV, Kang T, Sanwlani R, Van Deun J, Hendrix A, Mathivanan S. Vesiclepedia 2019: a compendium of RNA, proteins, lipids and metabolites in extracellular vesicles. Nucleic Acids Res. 2018;47:D516-9. 
50. Zeng Y. Principles of micro-RNA production and maturation. Oncogene. 2006;25:6156.

51. Lakshmipathy U, Hart RP. Concise review: MicroRNA expression in multipotent mesenchymal stromal cells. Stem Cells. 2008;26:356-63.

52. Lee $Y$, Jeon K, Lee JT, Kim S, Kim VN. MicroRNA maturation: stepwise processing and subcellular localization. EMBO J. 2002;21:4663-70.

53. Kosaka N, Iguchi H, Yoshioka Y, Takeshita F, Matsuki Y, Ochiya T. Secretory mechanisms and intercellular transfer of microRNAs in living cells. J Biol Chem. 2010. https://doi.org/10.1074/jbc.M110.107821.

54. Mittelbrunn M, Gutiérrez-Vázquez C, Villarroya-Beltri C, González S, Sánchez-Cabo F, González MÁ, Bernad A, Sánchez-Madrid F. Unidirectional transfer of microRNA-loaded exosomes from $T$ cells to antigen-presenting cells. Nat Commun. 2011;2:282.

55. Villarroya-Beltri C, Gutiérrez-Vázquez C, Sánchez-Cabo F, Pérez-Hernández D, Vázquez J, Martin-Cofreces N, Martinez-Herrera DJ, Pascual-Montano A, Mittelbrunn M, Sánchez-Madrid F. Sumoylated hnRNPA2B1 controls the sorting of miRNAs into exosomes through binding to specific motifs. Nat Commun. 2013;4:2980

56. Koppers-Lalic D, Hackenberg M, Bijnsdorp IV, van Eijndhoven MA, Sadek P, Sie D, Zini N, Middeldorp JM, Ylstra B, de Menezes RX. Nontemplated nucleotide additions distinguish the small RNA composition in cells from exosomes. Cell Rep. 2014;8:1649-58.

57. Arroyo JD, Chevillet JR, Kroh EM, Ruf IK, Pritchard CC, Gibson DF, Mitchell PS, Bennett CF, Pogosova-Agadjanyan EL, Stirewalt DL. Argonaute2 complexes carry a population of circulating microRNAs independent of vesicles in human plasma. Proc Natl Acad Sci U S A. 2011;108:5003-8.

58. Gourzones C, Ferrand F-R, Amiel C, Vérillaud B, Barat A, Guérin M, Gattolliat C-H, Gelin A, Klibi J, Chaaben AB. Consistent high concentration of the viral microRNA BART17 in plasma samples from nasopharyngeal carcinoma patients-evidence of non-exosomal transport. Virol J. 2013;10:119.

59. Statello L, Maugeri M, Garre E, Nawaz M, Wahlgren J, Papadimitriou A, Lundqvist C, Lindfors L, Collén A, Sunnerhagen P. Identification of RNAbinding proteins in exosomes capable of interacting with different types of RNA: RBP-facilitated transport of RNAs into exosomes. PLoS One. 2018;13: e0195969.

60. Melo SA, Sugimoto H, O'Connell JT, Kato N, Villanueva A, Vidal A, Qiu L, Vitkin E, Perelman LT, Melo CA. Cancer exosomes perform cellindependent microRNA biogenesis and promote tumorigenesis. Cancer Cell. 2014;26:707-21.

61. Cha DJ, Franklin JL, Dou Y, Liu Q, Higginbotham JN, Beckler MD, Weaver AM, Vickers K, Prasad N, Levy S. KRAS-dependent sorting of miRNA to exosomes. Elife. 2015:4:e07197.

62. McKenzie AJ, Hoshino D, Hong NH, Cha DJ, Franklin JL, Coffey RJ, Patton JG, Weaver AM. KRAS-MEK signaling controls Ago2 sorting into exosomes. Cell Rep. 2016;15:978-87.

63. Rekker K, Saare M, Roost AM, Kubo A-L, Zarovni N, Chiesi A, Salumets A, Peters M. Comparison of serum exosome isolation methods for microRNA profiling. Clin Biochem. 2014;47:135-8.

64. Jung KO, Youn H, Lee C-H, Kang KW, Chung J-K. Visualization of exosomemediated miR-210 transfer from hypoxic tumor cells. Oncotarget. 2017;8:9899.

65. Langevin S, Kuhnell D, Parry T, Biesiada J, Huang S, Wise-Draper T, Casper K, Zhang X, Medvedovic M, Kasper S. Comprehensive microRNA-sequencing of exosomes derived from head and neck carcinoma cells in vitro reveals common secretion profiles and potential utility as salivary biomarkers. Oncotarget. 2017;8:82459.

66. Guduric-Fuchs J, O'Connor A, Camp B, O'Neill CL, Medina RJ, Simpson DA. Selective extracellular vesicle-mediated export of an overlapping set of microRNAs from multiple cell types. BMC Genomics. 2012;13:357.

67. Azmi AS, Bao B, Sarkar FH. Exosomes in cancer development, metastasis, and drug resistance: a comprehensive review. Cancer Metastasis Rev. 2013;32:623-42.

68. S-b Y, Li Z-L, Luo D-h, B-j H, Chen Y-S, X-s Z, Cui J, Zeng Y-X, Li J. Tumorderived exosomes promote tumor progression and T-cell dysfunction through the regulation of enriched exosomal microRNAs in human nasopharyngeal carcinoma. Oncotarget. 2014;5:5439.

69. Lässer C, Théry C, Buzás El, Mathivanan S, Zhao W, Gho YS, Lötvall J. The International Society for Extracellular Vesicles launches the first massive open online course on extracellular vesicles: Taylor \& Francis. J Vesicles. 2016;5:34299.

70. Kogure T, Lin WL, Yan IK, Braconi C, Patel T. Intercellular nanovesiclemediated microRNA transfer: a mechanism of environmental modulation of hepatocellular cancer cell growth. Hepatology. 2011;54:1237-48.
71. Fabbri M, Paone A, Calore F, Galli R, Croce CM. A new role for microRNAs, as ligands of toll-like receptors. RNA Biol. 2013;10:169-74.

72. Fabbri M, Paone A, Calore F, Galli R, Gaudio E, Santhanam R, Lovat F, Fadda P, Mao C, Nuovo GJ. MicroRNAs bind to toll-like receptors to induce prometastatic inflammatory response. Proc Natl Acad Sci U S A. 2012;109:E2110-6.

73. Zhou W, Fong MY, Min Y, Somlo G, Liu L, Palomares MR, Yu Y, Chow A, O'Connor STF, Chin AR. Cancer-secreted miR-105 destroys vascular endothelial barriers to promote metastasis. Cancer Cell. 2014;25:501-15.

74. Liao J, Liu R, Shi Y-J, Yin L-H, Pu Y-P. Exosome-shuttling microRNA-21 promotes cell migration and invasion-targeting PDCD4 in esophageal cancer. Int J Oncol. 2016;48:2567-79.

75. Fong MY, Zhou W, Liu L, Alontaga AY, Chandra M, Ashby J, Chow A, O'Connor STF, Li S, Chin AR. Breast-cancer-secreted miR-122 reprograms glucose metabolism in premetastatic niche to promote metastasis. Nat Cell Biol. 2015;17:183.

76. Hood JL, San RS, Wickline SA. Exosomes released by melanoma cells prepare sentinel lymph nodes for tumor metastasis. Cancer Res. 2011; 71:3792-801.

77. Tonini T, Rossi F, Claudio PP. Molecular basis of angiogenesis and cancer. Oncogene. 2003;22:6549

78. Mao G, Liu Y, Fang X, Liu Y, Fang L, Lin L, Liu X, Wang N. Tumor-derived microRNA-494 promotes angiogenesis in non-small cell lung cancer. Angiogenesis. 2015;18:373-82.

79. Paggetti J, Haderk F, Seiffert M, Janji B, Distler U, Ammerlaan W, Kim YJ, Adam J, Lichter P, Solary E. Exosomes released by chronic lymphocytic leukemia cells induce the transition of stromal cells into cancer-associated fibroblasts. Blood. 2015. https://doi.org/10.1182/blood-2014-12-618025.

80. Sánchez CA, Andahur El, Valenzuela R, Castellon EA, Fulla JA, Ramos CG, Triviño JC. Exosomes from bulk and stem cells from human prostate cancer have a differential microRNA content that contributes cooperatively over local and pre-metastatic niche. Oncotarget. 2016;7:3993.

81. Umezu T, Ohyashiki K, Kuroda M, Ohyashiki J. Leukemia cell to endothelial cell communication via exosomal miRNAs. Oncogene. 2013;32:2747.

82. Kalinina N, Klink G, Glukhanyuk E, Lopatina T, Efimenko A, Akopyan Z. Tkachuk V: miR-92a regulates angiogenic activity of adipose-derived mesenchymal stromal cells. Exp Cell Res. 2015;339:61-6.

83. Lu J, Liu Q-H, Wang F, Tan J-J, Deng Y-Q, Peng X-H, Liu X, Zhang B, Xu X, Li X-P. Exosomal miR-9 inhibits angiogenesis by targeting MDK and regulating PDK/AKT pathway in nasopharyngeal carcinoma. J Exp Clin Cancer Res. 2018;37:147.

84. Zhuang G, Wu X, Jiang Z, Kasman I, Yao J, Guan Y, Oeh J, Modrusan Z, Bais C, Sampath D. Tumour-secreted miR-9 promotes endothelial cell migration and angiogenesis by activating the JAK-STAT pathway. EMBO J. 2012;31:3513-23.

85. Qu J, Lu D, Guo H, Miao W, Wu G, Zhou M. MicroRNA-9 regulates osteoblast differentiation and angiogenesis via the AMPK signaling pathway. Mol Cell Biochem. 2016;411:23-33.

86. R-s Q, Lin C, Ding G-P, Wu Z-R, Cao L-P. Increasing the immune activity of exosomes: the effect of miRNA-depleted exosome proteins on activating dendritic cell/cytokine-induced killer cells against pancreatic cancer. J Zhejiang Univ Sci B. 2016;17:352-60.

87. Vénéreau $E$, Ceriotti $C$, Bianchi ME. DAMPs from cell death to new life. Front Immunol. 2015;6:422.

88. Feitelson MA, Arzumanyan A, Kulathinal RJ, Blain SW, Holcombe RF, Mahajna J, Marino M, Martinez-Chantar ML, Nawroth R, Sanchez-Garcia I. Sustained proliferation in cancer: Mechanisms and novel therapeutic targets. Semin Cancer Biol. 2015;35:S25-54.

89. Yin $Y$, Cai $X$, Chen $X$, Liang H, Zhang Y, Li J, Wang Z, Chen X, Zhang W, Yokoyama S. Tumor-secreted miR-214 induces regulatory T cells: a major link between immune evasion and tumor growth. Cell Res. 2014;24:1164.

90. Hornick NI, Huan J, Doron B, Goloviznina NA, Lapidus J, Chang BH, Kurre P. Serum exosome microRNA as a minimally-invasive early biomarker of AML. Sci Rep. 2015;5:11295.

91. Huang $X$, Liang M, Dittmar R, Wang L. Extracellular microRNAs in urologic malignancies: chances and challenges. Int J Mol Sci. 2013;14:14785-99.

92. Armstrong DA, Green BB, Seigne JD, Schned AR, Marsit CJ. MicroRNA molecular profiling from matched tumor and bio-fluids in bladder cancer. Mol Cancer. 2015;14:194.

93. Rupp A-K, Rupp C, Keller S, Brase JC, Ehehalt R, Fogel M, Moldenhauer G, Marmé F, Sültmann H, Altevogt P. Loss of EpCAM expression in breast 
cancer derived serum exosomes: role of proteolytic cleavage. Gynecol Oncol. 2011;122:437-46.

94. He Y, Deng F, Yang S, Wang D, Chen X, Zhong S, Zhao J, Tang J. Exosomal microRNA: a novel biomarker for breast cancer. Biomark Med. 2018;12:177-88.

95. Liu J, Sun H, Wang X, Yu Q, Li S, Yu X, Gong W. Increased exosomal microRNA-21 and microRNA-146a levels in the cervicovaginal lavage specimens of patients with cervical cancer. Int J Mol Sci. 2014;15:758-73.

96. Ogata-Kawata H, Izumiya M, Kurioka D, Honma Y, Yamada Y, Furuta K, Gunji T, Ohta H, Okamoto H, Sonoda H. Circulating exosomal microRNAs as biomarkers of colon cancer. PLoS One. 2014:9:e92921.

97. Chiba M, Kimura M, Asari S. Exosomes secreted from human colorectal cancer cell lines contain mRNAs, microRNAs and natural antisense RNAs, that can transfer into the human hepatoma HepG2 and lung cancer A549 cell lines. Oncol Rep. 2012;28:1551-8.

98. Tanaka Y, Kamohara H, Kinoshita K, Kurashige J, Ishimoto T, Iwatsuki M, Watanabe M, Baba H. Clinical impact of serum exosomal microRNA-21 as a clinical biomarker in human esophageal squamous cell carcinoma. Cancer. 2013;119:1159-67.

99. Manterola L, Guruceaga E, Pérez-Larraya JG, González-Huarriz M, Jauregui P, Tejada S, Diez-Valle R, Segura V, Samprón N, Barrena C. A small noncoding RNA signature found in exosomes of GBM patient serum as a diagnostic tool. Neuro-Oncology. 2014;16:520-7.

100. Shi R, Wang P-Y, Li X-Y, Chen J-X, Li Y, Zhang X-Z, Zhang C-G, Jiang T, Li $W-B$, Ding W. Exosomal levels of miRNA-21 from cerebrospinal fluids associated with poor prognosis and tumor recurrence of glioma patients. Oncotarget. 2015;6:26971.

101. Molina-Pinelo S, Suárez R, Pastor MD, Nogal A, Márquez-Martín E, MartínJuan J, Carnero A, Paz-Ares L. Association between the miRNA signatures in plasma and bronchoalveolar fluid in respiratory pathologies. Dis Markers. 2012;32:221-30

102. Taylor DD, Gercel-Taylor C. MicroRNA signatures of tumor-derived exosomes as diagnostic biomarkers of ovarian cancer. Gynecol Oncol. 2008;110:13-21.

103. Rabinowits G, Gerçel-Taylor C, Day JM, Taylor DD, Kloecker GH. Exosomal microRNA: a diagnostic marker for lung cancer. Clin Lung Cancer. 2009;10: $42-6$.

104. Kruger S, Elmageed ZYA, Hawke DH, Wörner PM, Jansen DA, Abdel-Mageed $A B$, Alt EU, Izadpanah R. Molecular characterization of exosome-like vesicles from breast cancer cells. BMC Cancer. 2014;14:44.

105. Eichelser C, Stückrath I, Müller V, Milde-Langosch K, Wikman H, Pantel K, Schwarzenbach $\mathrm{H}$. Increased serum levels of circulating exosomal microRNA-373 in receptor-negative breast cancer patients. Oncotarget. 2014:5:9650.

106. Matsumura $T$, Sugimachi $K$, linuma $H$, Takahashi $Y$, Kurashige J, Sawada G, Ueda M, Uchi R, Ueo H, Takano Y. Exosomal microRNA in serum is a novel biomarker of recurrence in human colorectal cancer. Br J Cancer. 2015;113:275.

107. Samsonov R, Shtam T, Burdakov V, Glotov A, Tsyrlina E, Berstein L, Nosov A, Evtushenko V, Filatov M, Malek A. Lectin-induced agglutination method of urinary exosomes isolation followed by mi-RNA analysis: application for prostate cancer diagnostic. Prostate. 2016;76:68-79.

108. Kumar MS, Erkeland SJ, Pester RE, Chen CY, Ebert MS, Sharp PA, Jacks T. Suppression of non-small cell lung tumor development by the let-7 microRNA family. Proc Natl Acad Sci U S A. 2008;105:3903-8.

109. Montecalvo A, Larregina AT, Shufesky WJ, Stolz DB, Sullivan ML, Karlsson JM, Baty CJ, Gibson GA, Erdos G, Wang Z. Mechanism of transfer of functional microRNAs between mouse dendritic cells via exosomes. Blood. 2012;119:756-66.

110. Zhang Y, Liu D, Chen X, Li J, Li L, Bian Z, Sun F, Lu J, Yin Y, Cai X. Secreted monocytic miR-150 enhances targeted endothelial cell migration. Mol Cell. 2010;39:133-44

111. Yu B, Kim HW, Gong M, Wang J, Millard RW, Wang Y, Ashraf M, Xu M. Exosomes secreted from GATA-4 overexpressing mesenchymal stem cells serve as a reservoir of anti-apoptotic microRNAs for cardioprotection. Int J Cardiol. 2015;182:349-60.

112. S-i O, Takanashi M, Sudo K, Ueda S, Ishikawa A, Matsuyama N, Fujita K, Mizutani T, Ohgi T, Ochiya T. Systemically injected exosomes targeted to EGFR deliver antitumor microRNA to breast cancer cells. Mol Ther. 2013;21:185-91.

113. Kosaka N, Takeshita F, Yoshioka Y, Hagiwara K, Katsuda T, Ono M, Ochiya T. Exosomal tumor-suppressive microRNAs as novel cancer therapy:"exocure" is another choice for cancer treatment. Adv Drug Deliv Rev. 2013;65:376-82.
114. Lou G, Song X, Yang F, Wu S, Wang J, Chen Z, Liu Y. Exosomes derived from miR-122-modified adipose tissue-derived MSCs increase chemosensitivity of hepatocellular carcinoma. J Hematol Oncol. 2015;8:122.

115. Didiot M-C, Hall LM, Coles AH, Haraszti RA, Godinho BM, Chase K, Sapp E, Ly S, Alterman JF, Hassler MR. Exosome-mediated delivery of hydrophobically modified siRNA for huntingtin mRNA silencing. Mol Ther. 2016;24:1836-47.

116. Mukherjee B. Editorial (thematic issue:"Nanosize drug delivery system"). Curr Pharm Biotechnol. 2013;14:1221.

117. Leonard R, Williams S, Tulpule A, Levine A, Oliveros S. Improving the therapeutic index of anthracycline chemotherapy: focus on liposomal doxorubicin (Myocet ${ }^{\mathrm{T} M}$ ). Breast. 2009;18:218-24.

118. Petrelli F, Borgonovo K, Barni S. Targeted delivery for breast cancer therapy: the history of nanoparticle-albumin-bound paclitaxel. Expert Opin Pharmacother. 2010;11:1413-32.

119. Kanada M, Bachmann MH, Hardy JW, Frimannson DO, Bronsart L, Wang A, Sylvester MD, Schmidt TL, Kaspar RL, Butte MJ. Differential fates of biomolecules delivered to target cells via extracellular vesicles. Proc Natl Acad Sci U. S A. 2015;112:E1433-42.

120. Royo F, Falcon-Perez JM. Liver extracellular vesicles in health and disease. J Extracell Vesicles. 2012;1:18825.

121. Drommelschmidt K, Serdar M, Bendix I, Herz J, Bertling F, Prager S, Keller M, Ludwig A-K, Duhan V, Radtke S. Mesenchymal stem cell-derived extracellular vesicles ameliorate inflammation-induced preterm brain injury. Brain Behav Immun. 2017;60:220-32.

122. Ophelders DR, Wolfs TG, Jellema RK, Zwanenburg A, Andriessen P, Delhaas $T$, Ludwig A-K, Radtke S, Peters V, Janssen L. Mesenchymal stromal cellderived extracellular vesicles protect the fetal brain after hypoxia-ischemia. Stem Cells Transl Med. 2016;5:754-63.

123. Xitong $D$, Xiaorong $Z$. Targeted therapeutic delivery using engineered exosomes and its applications in cardiovascular diseases. Gene. 2016; 575:377-84.

124. Rupert DL, Claudio V, Lässer C, Bally M. Methods for the physical characterization and quantification of extracellular vesicles in biological samples. Biochim Biophys Acta Gen Subj. 1861;2017:3164-79.

125. Zhuang X, Xiang X, Grizzle W, Sun D, Zhang S, Axtell RC, Ju S, Mu J, Zhang $L$, Steinman L. Treatment of brain inflammatory diseases by delivering exosome encapsulated anti-inflammatory drugs from the nasal region to the brain. Mol Ther. 2011;19:1769-79.

126. Sun D, Zhuang X, Xiang X, Liu Y, Zhang S, Liu C, Barnes S, Grizzle W, Miller $D$, Zhang H-G. A novel nanoparticle drug delivery system: the antiinflammatory activity of curcumin is enhanced when encapsulated in exosomes. Mol Ther. 2010:18:1606-14.

127. Fuhrmann G, Serio A, Mazo M, Nair R, Stevens MM. Active loading into extracellular vesicles significantly improves the cellular uptake and photodynamic effect of porphyrins. J Control Release. 2015;205:35-44.

128. Kim MS, Haney MJ, Zhao Y, Mahajan V, Deygen I, Klyachko NL, Inskoe E, Piroyan A, Sokolsky M, Okolie O. Development of exosome-encapsulated paclitaxel to overcome MDR in cancer cells. Nanomedicine. 2016;12:655-64.

129. Alvarez-Erviti L, Seow Y, Yin H, Betts C, Lakhal S, Wood MJ. Delivery of siRNA to the mouse brain by systemic injection of targeted exosomes. Nat Biotechnol. 2011;29:341.

130. Shtam TA, Kovalev RA, Varfolomeeva EY, Makarov EM, Kil Y, Filatov MV. Exosomes are natural carriers of exogenous siRNA to human cells in vitro. Cell Commun Signal. 2013;11:88.

131. Wahlgren J, Karlson TDL, Brisslert M, Vaziri Sani F, Telemo E, Sunnerhagen P, Valadi H. Plasma exosomes can deliver exogenous short interfering RNA to monocytes and lymphocytes. Nucleic Acids Res. 2012;40:e130.

132. Lamichhane TN, Jeyaram A, Patel DB, Parajuli B, Livingston NK, Arumugasaamy N, Schardt JS, Jay SM. Oncogene knockdown via active loading of small RNAs into extracellular vesicles by sonication. Cell Mol Bioeng. 2016;9:315-24.

133. Lamichhane TN, Raiker RS, Jay SM. Exogenous DNA loading into extracellular vesicles via electroporation is size-dependent and enables limited gene delivery. Mol Pharm. 2015;12:3650-7.

134. Haney MJ, Klyachko NL, Zhao Y, Gupta R, Plotnikova EG, He Z, Patel T, Piroyan A, Sokolsky M, Kabanov AV. Exosomes as drug delivery vehicles for Parkinson's disease therapy. J Control Release. 2015;207:18-30.

135. Nakase I, Futaki S. Combined treatment with a pH-sensitive fusogenic peptide and cationic lipids achieves enhanced cytosolic delivery of exosomes. Sci Rep. 2015;5:10112. 
136. Lv L-H, Wan Y-L, Lin Y, Zhang W, Yang M, Li G-L, Lin H-M, Shang C-Z, Chen $Y-J$, Min J. Anticancer drugs cause release of exosomes with heat shock proteins from human hepatocellular carcinoma cells that elicit effective natural killer cell antitumor responses in vitro. J Biol Chem. 2012;287:15874-85.

137. Pascucci L, Coccè V, Bonomi A, Ami D, Ceccarelli P, Ciusani E, Viganò L, Locatelli A, Sisto F, Doglia SM. Paclitaxel is incorporated by mesenchymal stromal cells and released in exosomes that inhibit in vitro tumor growth: a new approach for drug delivery. J Control mRelease. 2014;192:262-70.

138. Lee J, Kim J, Jeong M, Lee H, Goh U, Kim H, Kim B, Park J-H. Liposomebased engineering of cells to package hydrophobic compounds in membrane vesicles for tumor penetration. Nano Lett. 2015;15:2938-44.

139. Lee J, Lee H, Goh U, Kim J, Jeong M, Lee J, Park J-H. Cellular engineering with membrane fusogenic liposomes to produce functionalized extracellular vesicles. ACS Appl Mater Interfaces. 2016:8:6790-5.

140. Liu Y, Li D, Liu Z, Zhou Y, Chu D, Li X, Jiang X, Hou D, Chen X, Chen Y. Targeted exosome-mediated delivery of opioid receptor Mu siRNA for the treatment of morphine relapse. Sci Rep. 2015;5:17543.

141. Gnecchi M, He H, Noiseux N, Liang OD, Zhang L, Morello F, Mu H, Melo LG, Pratt RE, Ingwall JS. Evidence supporting paracrine hypothesis for Aktmodified mesenchymal stem cell-mediated cardiac protection and functional improvement. FASEB J. 2006;20:661-9.

142. Sheldon H, Heikamp E, Turley H, Dragovic R, Thomas P, Oon CE, Leek R, Edelmann M, Kessler B, Sainson RC. New mechanism for notch signaling to endothelium at a distance by Delta-like 4 incorporation into exosomes. Blood. 2010;116:2385-94.

143. Mackie AR, Klyachko E, Thorne T, Schultz KM, Millay M, Ito A, Kamide CE, Liu T, Gupta R, Sahoo S. Sonic hedgehog-modified human CD34+ cells preserve cardiac function after acute myocardial infarction. Circ Res. 2012; 111:312-21.

144. Bianco NR, Kim SH, Ruffner MA, Robbins PD. Therapeutic effect of exosomes from indoleamine 2, 3-dioxygenase-positive dendritic cells in collageninduced arthritis and delayed-type hypersensitivity disease models. Arthritis Rheumatol. 2009;60:380-9.

145. Akao Y, Nakagawa Y, Hirata I, lio A, Itoh T, Kojima K, Nakashima R, Kitade Y, Naoe T. Role of anti-oncomirs miR-143 and-145 in human colorectal tumors. Cancer Gene Ther. 2010;17:398.

146. Salomon C, Ryan J, Sobrevia L, Kobayashi M, Ashman K, Mitchell M, Rice GE. Exosomal signaling during hypoxia mediates microvascular endothelial cell migration and vasculogenesis. PloS one. 2013;8:e68451.

147. Tadokoro H, Umezu T, Ohyashiki K, Hirano T, Ohyashiki JH. Exosomes derived from hypoxic leukemia cells enhance tube formation in endothelial cells. J Biol Chem. 2013;288:34343-51.

\section{Publisher's Note}

Springer Nature remains neutral with regard to jurisdictional claims in published maps and institutional affiliations.

Ready to submit your research? Choose BMC and benefit from:

- fast, convenient online submission

- thorough peer review by experienced researchers in your field

- rapid publication on acceptance

- support for research data, including large and complex data types

- gold Open Access which fosters wider collaboration and increased citations

- maximum visibility for your research: over $100 \mathrm{M}$ website views per year

At $\mathrm{BMC}$, research is always in progress.

Learn more biomedcentral.com/submissions 